\title{
Valor de Gulto das imagens de Maria
}

Recebido: 25/07/2017. Aprovado: 29/08/2017.

\section{Ana Carolina de Melo Coan*}

Resumo: O presente artigo tem como objetivo investigar as imagens católicas de Maria através da obra do filósofo Walter Benjamin. Para tal, primeiramente introduziremos o leitor à teoria benjaminiana acerca das fotografias e obras de arte focando nas noções de aura, tradição, valor de culto e valor de exibição. Num segundo momento apresentaremos a história do encontro da imagem de Nossa Senhora Aparecida e verificaremos, com base nos conceitos de Benjamin, se é possível identificar a presença da "aura" nas imagens marianas e quais são as condições que Ihes garantem este caráter. Por fim, dissertaremos brevemente sobre o valor de culto atribuído às imagens de Maria na difusão da fé e tradição católica.

Palavras-chave: Walter Benjamin. Aura. Imagem de Maria.

Abstract: The present paper proposes to investigate the catholic Marian images through the work of the philosopher Walter Benjamin. To do that, we will firstly introduce the reader to the aspects of Benjamin's theory concerning photography and works of art, focusing on the notions of aura, tradition, cult value and exhibition value. Secondly we will deal with some aspects of the history of the finding of Our Lady of Aparecida (Nossa Senhora Aparecida) and we will discuss, based on Benjamin's concepts, if it is possible to identify the presence of an "aura" in the Marian images and which conditions endow them with this character. Finally, we will dissert briefly on the cult value to the Marian images in the diffusion of catholic faith and tradition.

Keywords: Walter Benjamin. Aura. Marian images.

* Mestranda no Programa de Pós Graduação em Filosofia da Universidade Federal de Santa Catarina (UFSC), Florianópolis, SC, com pesquisa em Filosofia da Arte e Epistemologia. Bacharela e Licenciada em Filosofia pela Universidade Federal de Santa Catarina.

E-mail: acm.coan@gmail.com 


\section{Introdução}

De 12 de outubro de 2016 a 12 de outubro de 2017 celebra-se o Ano Nacional Mariano instituído pela Conferência Nacional dos Bispos do Brasil (CNBB) com o intuito de comemorar os 300 anos do encontro da imagem de Nossa Senhora Aparecida, no rio Paraíba do Sul. Em 2017 também se comemoram os 100 anos das aparições de Nossa Senhora de Fátima às três crianças em Portugal. Esse período de júbilo, responsável por marcar a devoção à figura de Maria no Brasil, trouxe consigo ações como a da peregrinação de réplicas, feitas a partir da imagem autêntica de Nossa Senhora Aparecida, por todo o país.

A partir do contato com uma dessas imagens foi que surgiu a inspiração para a escrita do presente artigo, uma vez que o valor de culto atribuído às imagens religiosas, como a de Nossa Senhora Aparecida, parece gerar e preservar algo muito semelhante com aquilo que o filósofo Walter Benjamin define como aura da obra de arte e que surge com as primeiras fotografias.

Como veremos adiante, Benjamin propõe que a aura é definida como o aqui e agora da obra, isto é, a aura tem um caráter de unicidade, que envolve significados e pertence a uma tradição. Contudo, os processos industriais cada vez mais desenvolvidos e fruto da demanda de uma sociedade imersa nos modos de consumo do capitalismo acabam destruindo-a.

O filósofo apresenta-nos esta problemática em textos como A Obra de Arte na Era de Sua Reprodutibilidade Técnica e Pequena História da Fotografia, onde afirma que as obras de arte acabam se tornando objetos comuns com pouco ou nenhum valor de culto e desprovidas de aura, ao passo que a técnica e o processo de reprodução das obras de arte ficaram mais simples e acessíveis.

No entanto, algo diferente parece acontecer com réplicas de imagens religiosas, pois estas, apesar de já possuírem valor de culto, uma vez que desempenham papel fundamental numa religião ou crença, também parecem criar e conservar uma atmosfera semelhante àquela possibilitada pelo caráter aurático presente nas primeiras fotografias.

Assim, nesse artigo faremos, inicialmente, uma breve exposição da teoria benjaminiana a respeito do conceito de aura, destacando a noção de tradição, valor de culto e valor de exposição. Num segundo momento faremos uma aproximação dos conceitos apresentados com o 
uso e significado das imagens religiosas, tomando como exemplo aqui a de Nossa Senhora Aparecida, para, por fim, verificarmos se é possível atribuirmos às imagens, réplicas ou original, de Maria, o caráter aurático que a primeira vista era exclusivo das primeiras fotografias.

\section{Walter Benjamin, fotografia e noção de aura}

O filósofo alemão Walter Benjamin, associado à Escola de Frankfurt e à Teoria Crítica, ao escrever o texto Pequena História da Fotografia, apresenta rapidamente o cenário de pesquisas e disputas que possibilitaram o surgimento da fotografia. Os primeiros retratos feitos pelo daguerreótipo ${ }^{1}$ eram placas de prata iodadas, com imagens pálidas e por serem peças únicas e raras eram guardadas em estojos como se fossem joias.

Diferentemente do que acontecia em retratos pintados, onde o resultado dependia exclusivamente da técnica e capacidade do artista, na fotografia surge algo de estranho e de novo.

Na vendedora de peixes de New Haven, olhando o chão com um recato tão displicente e tão sedutor, preserva-se algo que não se reduz ao gênio artístico do fotógrafo Hill, algo que não pode ser silenciado, que reclama com insistência o nome daquela que viveu ali que também na foto é real e que não quer extinguir-se na "arte".

A fotografia desta vendedora de peixes traz à tona toda uma atmosfera única que confere à obra seu caráter aurático. Mas o que é a aura? A aura "é uma figura singular composta de elementos espaciais e temporais: a aparição única de uma coisa distante, por mais próxima que ela esteja." ${ }^{3}$ Porém, ao fixar definitivamente a imagem humana através do daguerreótipo, a nova técnica é popularizada e passa a substituir os antigos retratistas, surgem os primeiros álbuns de fotografia, fotografias feitas em estúdios fotográficos e à medida que os mecanismos de produção e reprodução se tornaram mais sofisticados causaram a destruição da aura.

\footnotetext{
1 Primeira câmera fotográfica.

2 BENJAMIN, W. Pequena História da Fotografia. In: Obras Escolhidas: Magia e Técnica, Arte e Política. Ensaios sobre literatura e história da cultura, 3. ed. Tradução Sergio Paulo Rouanet. São Paulo: Brasiliense, 1987a. p. 93.

3 BENJAMIN, 1987a, p. 101.
} 
A noção de aura está diretamente ligada à noção de tradição que aparece em outro texto de Benjamin, chamado Experiência e Pobreza. Tradição aparece neste texto como a união pela narração e nele também há a denúncia do autor sobre uma geração pós-guerra que perde a capacidade de expressar e transmitir histórias e ensinamentos como resultado de horrores presenciados

Os livros de guerra que inundaram o mercado literário nos dez anos seguintes não continham experiências transmissiveis de boca em boca. Não, ofenômeno não é estranho. Porque nunca houve experiências mais radicalmente desmoralizadas que a experiencia estratégica pela guerra de trincheiras, a experiência econômica pela inflação, a experiência do corpo pela fome, a experiência moral pelos governantes. Uma geração que ainda fora à escola num bonde puxado por cavalos viu-se abandonada, sem teto, numa paisagem diferente em tudo, exceto nas nuvens, e em cujo centro, num campo de forças de correntes explosões destruidoras, estava of frágil e minúsculo corpo humano. ${ }^{4}$

O caráter aurático existente nas primeiras fotografias é destruído na medida em que o monstruoso desenvolvimento da técnica criou uma nova forma de miséria que se sobrepõe ao homem. Há, nos indivíduos modernos, a necessidade exacerbada de consumir, de novidades e da hiper-estimulação, contraposta ao descuido com as relações humanas e as construções sociais que a partir destas proviriam.

Em A Obra de Arte na Era de sua Reprodutibilidade Técnica o filósofo ressalta que "a unicidade da obra de arte é idêntica à sua inserção no contexto da tradição. Sem dúvida, essa tradição é algo de muito vivo e extraordinariamente variável." "5 Deste modo é razoável aceitar que a forma mais primitiva de inserir uma obra de arte no contexto de uma tradição exprimia-se através do culto, posto que as primeiras obras de arte surgem com uma função ritualística e posteriormente religiosa ou, como diria Benjamin, "o valor único da obra de arte 'autêntica' tem sempre um fundamento teológico, por mais remoto que seja."

4 BENJAMIN, W. Experiência e Pobreza. In: Obras Escolhidas: Magia e Técnica, Arte e Política. Ensaios sobre literatura e história da cultura, 3. ed. Tradução Sergio Paulo Rouanet. São Paulo: Brasiliense, 1987b. p. 115

5 BENJAMIN, W. A Obra de Arte na Era de Sua Reprodutibilidade Técnica. In: Obras Escolhidas: Magia e Técnica, Arte e Política. Ensaios sobre literatura e história da cultura, 3. ed. Tradução Sergio Paulo Rouanet. São Paulo: Brasiliense, 1987c. p. 170 e 171.

6 BENJAMIN, 1987c, p. 171. 
Todavia, a reprodutibilidade técnica permitiu a emancipação da obra de arte, pela primeira vez na história, de sua função ritualística. Como a discussão sobre autenticidade parece perder o sentido dentro do novo estilo de produção artística a função social da arte muda, "em vez de fundar-se no ritual, ela passa a fundar-se em outra práxis: a política." Ao concernir à história da arte é possível identificar a mudança, mencionada pelo autor, do valor de culto para o valor de exposição das obras.

Como dissemos anteriormente, as obras de arte surgem como imagens a serviço do mágico, do ritualístico e do religioso, não obstante sendo levadas pelo valor de culto a serem predominantemente veladas, secretas e exclusivas a um grupo muito seleto. "Certas estátuas divinas somente são acessíveis ao sumo sacerdote, na cella, certas madonas permanecem cobertas quase $o$ ano inteiro, certas esculturas em catedrais da Idade Média são invisíveis, do solo, para o observador."»

À proporção que a reprodutibilidade técnica se estabelece, o valor de culto das obras de arte é sucedido pelo valor de exposição visto que estas, ao se tornarem emancipadas de sua função originária, conquistam mais visibilidade. "A exponibilidade de um busto, que pode ser deslocado de um lugar para outro, é maior do que uma estátua divina, que tem sua sede fixa no interior de um templo. A exponibilidade de um quadro é maior que a de um mosaico ou de um afresco, que o precederam."

Esta transição do valor de culto de uma obra para o valor de sua exponibilidade reclama a superficialidade e falta de uma real experiência estética das obras de arte, resultando, por exemplo, na destruição da aura nas fotografias. Reportando-nos à história da arte e suas funções temos, portanto, o seguinte movimento:

A arte registrava certas imagens, a serviço da magia, com funções práticas: seja como execução de atividades mágicas, seja a título de ensinamento dessas práticas mágicas, seja como objeto de contemplação, à qual se atribuíam efeitos mágicos. Os temas dessa arte eram o homem e seu meio, copiados segundo as exigências de uma sociedade cuja técnica se fundia inteiramente com o ritual. Essa sociedade é a antitese da nossa, cuja técnica é a mais emancipada que jamais existiu. Mas, essa técnica emancipada se confronta com a sociedade moderna

\footnotetext{
BENJAMIN, 1987c, p. 171 e 172.

8 BENJAMIN, 1987c, p. 173.

9 BENJAMIN, 1987c, p. 173.
} 
sob a forma de uma segunda natureza, não menos elementar que a da sociedade primitiva, como provam as guerras e as crises econômicas. Diante dessa segunda natureza, que o homem inventou mas há muito não controla, somos obrigados a aprender, como outrora diante da primeira. Mais uma vez, a arte põe-se a serviço desse aprendizado. ${ }^{10}$

O cerne da teoria benjaminiana acerca da aura reside, então, numa preocupação social mediante os efeitos de um sistema de produção em larga escala que parece atingir maleficamente a sociedade moderna. Para Walter Benjamin a aura surge e sucumbe com os avanços técnicos que permitiram à humanidade desenvolver e melhorar a fotografia. Porém, a noção de aura que apresentamos sucintamente parece ser captada por outros tipos de obra como, por exemplo, as imagens religiosas. Investigaremos na segunda parte deste artigo a possibilidade da efetivação deste suposto usando especificamente a imagem de Nossa Senhora Aparecida.

\section{Imagens e devoção a Nossa Senhora Aparecida}

Às vésperas do tricentésimo aniversário do encontro da imagem de Nossa Senhora da Conceição Aparecida, apresentaremos rapidamente sua história. Segundo registros do Santuário Nacional de Nossa Senhora Aparecida ${ }^{11}$ a imagem foi encontrada em meados de 1717 por três pescadores que saíram em busca de peixes para o banquete que a Vila de Santo Antônio de Guaratinguetá ofereceria a Dom Pedro de Almeida e Portugal, governador da Província de São Paulo e Minas Gerais, e sua comitiva. Após tentativas frustradas e com redes vazias puxadas do rio Paraíba, conta-se que os pescadores Domingos Garcia, Filipe Pedroso e João Alves encarregados da pesca, fizeram, com muita fé, uma oração pedindo pela intercessão de Maria, mãe de Deus. Foi então na altura do Porto de Itaguaçu, aproximadamente, que ao laçar as redes encontraram uma imagem de um corpo feminino sem cabeça. Num segundo lançamento, a rede puxada pelos pescadores trouxe, enroscada em seus fios, a cabeça que pertencia ao corpo da imagem. Após unirem cabeça e corpo, as demais redes lançadas ao rio voltaram repletas de peixes, garantindo a fartura do banquete. A imagem da Santa, feita de terracota, foi entregue a Silvana da Rocha Alves, esposa de Domingos, irmã de Felipe e mãe de

10 BENJAMIN, 1987c, p. 173 e 174.

11 PORTAL A12. História de Nossa Senhora Aparecida. Disponível em: <http://www.a12. com/santuario-nacional/institucional/detalhes/historia-de-nossa-senhora-aparecida>. Acesso em: 22 ago. 2017. 
João, que tratou de colar as partes com cera, colocando-a num altar, dando início assim à devoção a Nossa Senhora Aparecida. A imagem original da Santa encontra-se atualmente no Santuário Nacional de Nossa Senhora da Conceição Aparecida, que é o maior santuário no mundo dedicado a Maria ${ }^{12}$, localizado na cidade de Aparecida, no Estado de São Paulo.

Mediante este acontecimento, parece ser inegável o fato da imagem encontrada e consagrada estar envolta por uma aura, nos termos benjaminianos, à medida que esta carrega um sentimento de aqui e agora muito forte não somente para os religiosos e fiéis da Santa, mas para todos aqueles que reconhecem sua imagem como um objeto de valor histórico e cultural tal qual uma obra de arte. Mas, será que esta aura é preservada nas imagens peregrinas ${ }^{13} \mathrm{ou}$, ainda, será possível às diversas cópias e versões da imagem da Santa possuir aura?

Parece razoável, prima facie, dizer que a imagem autêntica da Santa possui valor incomparável com as demais. Entretanto, isso por si só não interfere no carinho, cuidado e devoção com que os fiéis dirigem-se para as cópias, autênticas ou não, da imagem da Santa. Afinal, este fato apenas é possível justamente porque o objeto de devoção está para além da imagem física. Conquanto o problema enfrentado pelas fotografias e demais obras de arte reproduzíveis também é um problema enfrentado pelas imagens religiosas.

Todas as imagens religiosas carregam consigo a potencialidade do caráter aurático, uma vez que são representação do sagrado, guarnecido por uma tradição e com valor de culto implementado por esta. Mas ser cópia de uma imagem, sagrada ou religiosa, não garante em si a existência da aura, uma vez que essa pode ser usada para fins outros, como por exemplo, decoração. A aura de uma imagem só pode ser garantida se situada dentro de um escopo simbólico de significação de uma cultura.

É justamente por isto que fatos, como o atentado à imagem original de Nossa Senhora Aparecida em $1978^{14}$, não oferecem riscos ao caráter

12 PORTALA12. Santuário Nacional de Nossa Senhora Aparecida. Disponível em: <http:// www.a12.com/santuario-nacional/institucional/detalhes/santuario-nacional-de-nossa-senhora-aparecida>. Acesso em: 22 ago. 2017.

13 As imagens peregrinas de Nossa Senhora Aparecida são réplicas feitas a partir da imagem original da Santa e estão circulando por todo Brasil neste Ano Mariano.

14 BENJAMIN, L. 38 anos do atentado da Imagem de Nossa Senhora Aparecida. Santuário Nacional de Nossa Senhora da Aparecida, 2016. Disponível em: <http://www. a12.com/santuario-nacional/noticias/detalhes/38-anos-do-atentado-da-imagem-de-nossa-senhora-aparecida>. Acesso em: 22 ago. 2017. 
aurático da mesma. Pois, como já dissemos, o caráter de unicidade transcende o objeto e é garantido pelo valor de culto construído pela tradição a qual este pertence.

Para os católicos, Maria é reverenciada como mãe do Filho de Deus encarnado, Jesus Cristo, e recebe o título de rainha e mãe da Igreja. Alguns autores dedicados à Mariologia, como Afonso Murad ${ }^{15}$, Jaroslav Pelikan ${ }^{16}$ e George Henry Tarvard ${ }^{17}$, apresentam, similarmente, que Maria é aquela que melhor personifica o Evangelho ou, dito de outro modo, Maria é o Evangelho vivido. Ela, como fiel ouvinte da Palavra e mulher de fé, acolhe o mistério e frutifica a partir dessa acolhida.

No texto Maria através dos séculos: seu papel na história da cultura, Pelikan afirma que a figura de Maria incita tamanha devoção devido ao misticismo mariano efetivado, por exemplo, através de preces e orações dedicadas a ela.

Como a ambição do mistico é se alçar ao invisível por meio do visivel e às coisas celestes por meio das terrenas, essas preces dirigidas a Maria tiveram início em sua simples personalidade histórica e em sua humilde vida terrena para depois se elevarem à posição especial por ela ocupada no reino de Deus e a seu papel sem par no universo. Além disso, essa visão mística da Virgem não almejava apenas uma alegria passiva, mas acreditava-se que ela possuísse um poder transformador, provado pelos que tiveram o privilégio de ver a Rainha do Céu e acabaram por dedicar suas vidas ao seu serviço. ${ }^{18}$

Destarte, a figura de Maria desempenha papel fundamental no catolicismo ao passo que, além de ter gerado, nutrido e zelado por seu Filho, é exemplo de mulher, serva e mãe. Maria também é responsável por testemunhar em prol do evangelho da misericórdia divina, visto em Jesus Cristo, como caminho promotor de mudanças nas pessoas e no mundo.

São conjecturas como essas apresentadas brevemente que possibilitam a presença do caráter aurático a qualquer imagem de Maria, sejam estas históricas, adornadas ou singelas. Mas, assim como a repro-

15 MURAD, A. Maria toda de Deus e tão humana: compêndio de Mariologia. São Paulo: Paulinas: Santuário, 2012.

16 PELIKAN, J. Maria através dos séculos: seu papel na história da cultura. São Paulo: Companhia das Letras, 2000.

17 TAVARD, G. H. As múltiplas faces da Virgem Maria. São Paulo: Paulus, 1999.

18 PELIKAN, 2000, p. 293-294. 
dutibilidade técnica, fruto de seu contexto histórico, social e político, foi responsável pela destruição da aura das fotografias, algo similar pode acontecer com as imagens religiosas.

A aura das imagens de Nossa Senhora pode desmantelar-se posto que o católico vive atualmente num mundo secularizado, superficial e distante da fé, resultando, desse modo, no descaso com a real significação da figura de Maria emanada de sua imagem. Tal qual Benjamin propôs como resolução desse impasse no caso das obras de arte, devemos aqui constantemente nos colocar na posição de humildes aprendizes, ou seja, é necessário que o católico não se acomode e sim revisite e ressignifique constantemente aquilo que orienta sua prática e sua fé.

\section{Considerações Finais}

Explicitamos rapidamente a teoria de Walter Benjamin acerca da aura, apresentando e esclarecendo os conceitos de tradição, valor de culto e valor de exposição como necessários para entender o que é esta aura presente nas primeiras fotografias e destruída, posteriormente, com a reprodutibilidade técnica.

Como vimos, aura é a aparição de algo que está longe e perto ao mesmo tempo, em outras palavras, é aquilo que reúne em si um contexto simbólico de significação que só pode ser apreendido por aqueles que compreendem e/ou estão inseridos nele.

Ao analisarmos a noção de aura pudemos razoavelmente afirmar que é possível encontrar fenômeno semelhante materializado nas imagens de Nossa Senhora Aparecida. Contudo, a possibilidade da existência de aura nas imagens de Maria é inerente à possibilidade de sua destruição. Isso pode acontecer à proporção que o católico imerso no mundo secular passa a enxergar a imagem de Maria como um objeto cotidiano sem o devido cuidado.

Por fim, o católico ciente da importância de Maria dentro de sua fé e prática religiosa deve esmerar-se e vivificar este fato sempre que encontrar-se com uma de suas imagens, não só a fim de manter sua aura, mas, acima disso, reavivar sua missão de ser, como ela, sal da terra e luz do mundo ${ }^{19}$.

19 CNBB. Cristãos leigos e leigas na lgreja e na sociedade: sal da Terra e luz do Mundo (Mt 5, 13-14). Brasília: CNBB, 2016. p. 67-68; n. 113-115. 


\section{Referências}

BENJAMIN, W. Pequena história da fotografia. In: Obras Escolhidas: Magia e Técnica, Arte e Política. Ensaios sobre literatura e história da cultura, 3. ed. Tradução Sergio Paulo Rouanet. São Paulo: Brasiliense, 1987a. p. 91-107.

. Experiência e pobreza. In: Obras Escolhidas: Magia e Técnica, Arte e Política. Ensaios sobre literatura e história da cultura, 3. ed. Tradução Sergio Paulo Rouanet. São Paulo: Brasiliense, 1987b. p. 114-119.

A obra de arte na era de sua reprodutibilidade técnica. In: Obras Escolhidas: Magia e Técnica, Arte e Política. Ensaios sobre literatura e história da cultura, 3. ed. Tradução Sergio Paulo Rouanet. São Paulo: Brasiliense, 1987c. p. 165-196.

BENJAMIN, L. 38 anos do atentado da Imagem de Nossa Senhora Aparecida. Santuário Nacional de Nossa Senhora da Aparecida, 2016. Disponível em: <http://www.a12.com/santuario-nacional/noticias/ detalhes/38-anos-do-atentado-da-imagem-de-nossa-senhora-aparecida $>$. Acesso em: 22 ago. 2017.

CNBB. Cristãos leigos e leigas na Igreja e na sociedade: sal da terra e luz do mundo (Mt 5, 13-14). Brasília: CNBB, 2016.

MURAD, A. Maria toda de Deus e tão humana: compêndio de Mariologia. São Paulo: Paulinas: Santuário, 2012.

PELIKAN, J. Maria através dos séculos: seu papel na história da cultura. São Paulo: Companhia das Letras, 2000.

PORTAL A12. História de Nossa Senhora Aparecida. Disponível em: $<$ http://www.a12.com/santuario-nacional/institucional/detalhes/historia-de-nossa-senhora-aparecida $>$. Acesso em: 22 ago. 2017.

. Santuário Nacional de Nossa Senhora Aparecida. Disponível em: $<\mathrm{http}: / / \mathrm{www} \cdot \mathrm{a} 12 . \mathrm{com} /$ santuario-nacional/institucional/detalhes/santuario-nacional-de-nossa-senhora-aparecida $>$. Acesso em: 22 ago. 2017.

TAVARD, G. H. As múltiplas faces da Virgem Maria. São Paulo: Paulus, 1999. 